\title{
Effect of algal flocculation on dissolved organic matters using cationic starch modified soils
}

\author{
Wenqing Shi ${ }^{1}$, Lei $\mathrm{Bi}^{1}$, Gang Pan ${ }^{1,2, *}$ \\ 1. Research Center for Eco-Environmental Sciences, Chinese Academy of Sciences, Beijing 100085, China. \\ E-mail: shiwenqing2005320@126.com \\ 2. School of Animal, Rural, and Environmental Sciences, Nottingham Trent University, NG25 OQF, UK
}

\section{A R T I C L E I N F O}

Article history:

Received 13 October 2015

Revised 14 December 2015

Accepted 15 December 2015

Available online 13 February 2016

Keywords:

Cyanobacterial bloom

Cationic starch

Modified soil

Charge density

Dissolved organic carbon

\begin{abstract}
A B S T R A C T
Modified soils (MSs) are being increasingly used as geo-engineering materials for the sedimentation removal of cyanobacterial blooms. Cationic starch (CS) has been tested as an effective soil modifier, but little is known about its potential impacts on the treated water. This study investigated dissolved organic matters in the bloom water after algal removal using cationic starch modified soils (CS-MSs). Results showed that the dissolved organic carbon (DOC) could be decreased by CS-MS flocculation and the use of higher charge density CS yielded a greater DOC reduction. When CS with the charge density of $0.052,0.102$ and $0.293 \mathrm{meq} / \mathrm{g}$ were used, DOC was decreased from 3.4 to $3.0,2.3$ and $1.7 \mathrm{mg} / \mathrm{L}$, respectively. The excitation-emission matrix fluorescence spectroscopy and $\mathrm{UV}_{254}$ analysis indicated that CS-MS exhibits an ability to remove some soluble organics, which contributed to the DOC reduction. However, the use of low charge density CS posed a potential risk of DOC increase due to the high CS loading for effective algal removal. When CS with the charge density of $0.044 \mathrm{meq} / \mathrm{g}$ was used, DOC was increased from 3.4 to $3.9 \mathrm{mg} / \mathrm{L}$. This study suggested, when CS-MS is used for cyanobacterial bloom removal, the content of dissolved organic matters in the treated water can be controlled by optimizing the charge density of CS. For the settled organic matters, other measures (e.g., capping treatments using oxygen loaded materials) should be jointly applied after algal flocculation.

(c) 2016 The Research Center for Eco-Environmental Sciences, Chinese Academy of Sciences.
\end{abstract}

Published by Elsevier B.V.

\section{Introduction}

When a certain management option is used for the damaged ecosystem restoration, it is essential to consider also any potential unintentional impacts associated with amendment products (Spears et al., 2013). The frequent outbreak of cyanobacterial blooms in eutrophic waters is a global issue, posing serious threats to aquatic ecosystem and human health (Chen et al., 2006; Liu and Le, 2015; Lu et al., 2013; Wang et al., 2013c). Modified soils (MSs) have triggered great interest as geo-engineering materials for cyanobacterial bloom control in recent years (Lürling and van Oosterhout, 2013; Mackay et al., 2014; Spears et al., 2014; Tian et al., 2014). Although many studies on algal removal using MSs have been reported (Li and Pan, 2013; Pan et al., 2011a; Shi et al., 2015; Zou et al., 2005), little is known about its potential impacts on the receiving waters.

In the MS method, modifiers are used to offer soil particles the abilities of charge neutralization and bridging, and make them obtain flocculation potential for cyanobacterial cells ( $\mathrm{Li}$ and Pan, 2013; Pan et al., 2011a). Several chemical coagulants

\footnotetext{
* Corresponding author. E-mail: gpan@rcees.ac.cn (Gang Pan).
} 
(e.g., aluminum and ferric salts) and organic macromolecular flocculants (e.g., cationic starch, chitosan and Moringa oleifera) have been tested as soil modifiers for algal removal (Dai et al., 2015; Li and Pan, 2013; Pan et al., 2006; Shi et al., 2015). Compared with chemical coagulants, organic macromolecular flocculants are often easily biodegradable, eco-friendly and are well accepted by the public (Mukherjee et al., 2014; Ndabigengesere and Narasiah, 1998; Renault et al., 2009). However, when these organic flocculants are sprayed into natural waters, a major concern is the likelihood of dissolved organic matter (DOM) increase in water column. The DOM is a storage pool of nitrogen and phosphorous and an important contributor of biochemical/chemical oxygen demand in eutrophic waters (Bushaw et al., 1996; Qu et al., 2013). The increase of DOM may result in the lost of water quality and the rapid oxygen depletion in the receiving water (Evans et al., 2005; Mermillod-Blondin et al., 2005). However, to date, the use of organic flocculants in MSs has mainly focused on algal removal effect with little consideration of its impacts on DOM in the treated bloom water.

Algae particles are negatively charged, which can stably suspend in water column (Chen et al., 2004). Charge neutralization is a main mechanism operating algal flocculation using MSs, which can reduce the electrostatic repulsion and promote aggregation between MSs and algae particles (Li and Pan, 2013; Shi et al., 2015). To achieve the effective algal removal, desired amount of positive charges are needed to neutralize negative charges on algal cell surface (Li and Pan, 2015; Li et al., 2015). Thus, the charge density may potentially affect the loadings of modifiers, which are directly related to the residual DOM in the treated water. Indentifying and understanding this effect are essential to develop strategies for DOM content control when MS is used for cyanobacterial bloom removal in natural waters.

In this study, a series of cationic starch (CS) with different charge densities were used as soil modifiers (CS-MSs). The flocculation of Microcystis aeruginosa (M. aeruginosa) using each CS-MSs were conducted by jar tests. Dissolved organic carbon (DOC), UV absorbance at $254 \mathrm{~nm}\left(\mathrm{UV}_{254}\right)$ and excitationemission matrix (EEM) fluorescence spectra were used to analyze the DOM after algal removal. The objective of this study is to explore the effect of algal flocculation on DOM in bloom waters using CS-MSs.

\section{Materials and methods}

\subsection{Algal species and culture}

M. aeruginosa, a common freshwater bloom-forming cyanobacterium, was used in this study. The M. aeruginosa cells (FACHB-905) were obtained from the Institute of Hydrobiology, Chinese Academy of Sciences, and cultivated in BG11 medium. The BG11 medium was composed of $1500 \mathrm{mg} / \mathrm{L}$ $\mathrm{NaNO}_{3}, 75 \mathrm{mg} / \mathrm{L} \quad \mathrm{MgSO}_{4} \cdot 7 \mathrm{H}_{2} \mathrm{O}, 40 \mathrm{mg} / \mathrm{L} \quad \mathrm{K}_{2} \mathrm{HPO}_{4}, 36 \mathrm{mg} / \mathrm{L}$ $\mathrm{CaCl}_{2} \cdot 2 \mathrm{H}_{2} \mathrm{O}, 20 \mathrm{mg} / \mathrm{L} \mathrm{Na}_{2} \mathrm{CO}_{3}, 6 \mathrm{mg} / \mathrm{L}$ citric acid monohydrate, $6 \mathrm{mg} / \mathrm{L}$ ferric ammonium citrate, $2.86 \mathrm{mg} / \mathrm{L} \mathrm{H}_{3} \mathrm{BO}_{3}, 1.86 \mathrm{mg} / \mathrm{L}$ $\mathrm{MnCl}_{2} \cdot 4 \mathrm{H}_{2} \mathrm{O}, 1 \mathrm{mg} / \mathrm{L} \quad \mathrm{Na}_{2}$ EDTA, $0.39 \mathrm{mg} / \mathrm{L} \quad \mathrm{Na}_{2} \mathrm{MoO}_{4} \cdot 2 \mathrm{H}_{2} \mathrm{O}$, $0.22 \mathrm{mg} / \mathrm{L} \mathrm{ZnSO} \cdot 7 \mathrm{H}_{2} \mathrm{O}, 0.08 \mathrm{mg} / \mathrm{L} \mathrm{CuSO}_{4} \cdot 5 \mathrm{H}_{2} \mathrm{O}$, and $0.05 \mathrm{mg} / \mathrm{L}$ $\mathrm{Co}\left(\mathrm{NO}_{3}\right)_{2} \cdot 6 \mathrm{H}_{2} \mathrm{O}$. Algal batch cultures were maintained at $25 \pm 1^{\circ} \mathrm{C}$ under continuous cool white fluorescent light of 2000-3000 lx on a $12 \mathrm{hr}$ light and $12 \mathrm{hr}$ darkness regimen in an illuminating incubator (LRH-250-G, Guangdong Medical Apparatus Co. Ltd., China).

\subsection{Cationic starch modified soils}

CS was prepared by reacting corn starch (Unilever Co. Ltd., China) with cationic monomer, 2,3-epoxypropyl trimethyl ammonium chloride (GTA), using the microwave-assisted method (Lin et al., 2012). The details of the synthesis are as follows: $0.5 \mathrm{~g}$ GTA was dissolved in $100 \mathrm{~mL}$ of $5.0 \mathrm{~g} / \mathrm{L} \mathrm{NaOH}$ solution with constant stirring for $10 \mathrm{~min}$. Ten grams of starch was added to the above mixture and stirring was continued for another $30 \mathrm{~min}$ at a $70^{\circ} \mathrm{C}$ water-bath. Then, the reaction vessel was placed on the turntable of a domestic microwave oven (Guangdong Galanz Group Co. Ltd., China) and irradiated at the power of $750 \mathrm{~W}$ with periodic pause to avoid boiling. This microwave irradiation-cooling cycle was continued until a viscous gel-like mass formed. After being cooled down to room temperature, the gel-like mass was washed with ethanol for three times, dried in a vacuum oven (DZF-6020, Shanghai Yiheng Instrument Co. Ltd., China) at $50^{\circ} \mathrm{C}$ for $6 \mathrm{hr}$ and then pulverized before use. The obtained product is termed $\mathrm{CS}_{0.5: 10}$ (0.5:10 is the mass ratio of GTA to starch). Using this method, $\mathrm{CS}_{1.0: 10}, \mathrm{CS}_{1.5: 10}$ and $\mathrm{CS}_{2.5: 10}$ were synthesized. As the mass ratio of GTA to starch increased, the charge density and degree of substitution of CS increased, but the intrinsic viscosity and molecular weight showed no significant changes (t-test, $p<0.05)$ (Table 1 ).

The soil used was collected from the bank of Meiliang Bay, Lake Taihu (China). This bay has suffered from severe cyanobacterial blooms over the past years, and MS materials have been tested to settle the blooms (Pan et al., 2006, 2011b). The soil sample was grounded and sieved (180 meshes) before use. For CS-MS preparation, a certain amount of CS was used to modify the soil suspension according to the dose conditions tested. The soil concentration used in all the flocculation experiments was fixed to $100 \mathrm{mg} / \mathrm{L}$. The surface charge of soil and CS-MS particles was characterized using a Zetasizer 2000 (Malvern Co. UK).

\section{Table 1 - The properties of cationic starch.}

\begin{tabular}{lcccc} 
& $\begin{array}{c}\text { Charge } \\
\text { density }^{\mathrm{a}} \\
(\mathrm{meq} / \mathrm{g})\end{array}$ & $\begin{array}{c}\text { Degree of } \\
\text { substitution }^{\mathrm{b}}\end{array}$ & $\begin{array}{c}\text { Intrinsic } \\
\left.\text { viscosity }^{\mathrm{c}}{ }^{\mathrm{d}} / \mathrm{g}\right)\end{array}$ & $\begin{array}{c}\text { Molecular } \\
\text { weight }^{\mathrm{d}} \\
\left(\times 10^{5}\right)\end{array}$ \\
\hline Native & 0 & 0 & 1.21 & 4.27 \\
starch & 0 & 0.073 & 1.31 & 4.67 \\
$\mathrm{CS}_{0.5: 10}$ & 0.044 & 0.092 & 1.24 & 4.39 \\
$\mathrm{CS}_{1.0: 10}$ & 0.052 & 0.166 & 1.30 & 4.63 \\
$\mathrm{CS}_{1.5: 10}$ & 0.102 & 0.255 & 1.08 & 3.76 \\
$\mathrm{CS}_{2.5: 10}$ & 0.293 & &
\end{tabular}

a Determined using the polyelectrolyte titration method (Kam and Gregory, 1999).

b Determined using one point method (Ahmad et al., 1999).

c Determined using element analysis method (Lin et al., 2012).

d Calculated based on the Mark-Houwink relationship taking ' $k$ ' as $1.18 \times 10^{-3}$ and ' $a$ ' as 0.89 (Ahmad et al., 1999). 


\subsection{Algal flocculation}

Flocculation experiments were conducted in a jar test apparatus (ZR3-6, Zhongrun Water Industry Technology Development Co. Ltd., China) using M. aeruginosa cultures in mid- to late-exponential growth phase. The initial cell concentration for all the flocculation experiments was set to $3.2 \times 10^{9}$ cells/L. Two hundred milliliters of readily prepared M. aeruginosa solution was transferred to $300-\mathrm{mL}$ beaker, and then stirred at $200 \mathrm{r} / \mathrm{min}$ for $1 \mathrm{~min}$ and $40 \mathrm{r} / \mathrm{min}$ for another $5 \mathrm{~min}$ after CS-MS were added. The control was run in the abovementioned $M$. aeruginosa solution without adding any soil or CS. The flocculation experiments were conducted at raw algal solution $\mathrm{pH}$ of 8.60 . The $\mathrm{pH}$ kept at $8.60 \pm 0.2$ after the addition of CS-MSs. All the flocculation experiments were conducted in triplicate.

Samples were collected from $2 \mathrm{~cm}$ below the water surface after floc sedimentation for $30 \mathrm{~min}$ to enumerate the cell number using an Axioskop 2 mot plus microscope (Carl ZEISS, Germany). The algal removal efficiency was calculated as: (initial cell concentration - sample cell concentration) / initial cell concentration $\times 100 \%$. After algal flocculation, $10 \mathrm{~mL}$ water sample was also collected to investigate the cell surface charge using a Zetasizer 2000 (Malvern Co., UK).

\subsection{DOM analysis}

DOM analysis was performed after algal sedimentation by measuring DOC, $U_{254}$ and EEM spectra. Water samples were filtered through $0.45-\mu \mathrm{m}$ membrane filters before analysis. DOC was measured using a total organic carbon (TOC) analyzer (Liqui TOC II, Elementar, Germany). UV $_{254}$ was determined using an UV-Vis spectrophotometer (756PC, Shanghai Sunny Hengping Scientific Instrument Co. Ltd., China) at $254 \mathrm{~nm}$ with a quartz cell path of $1 \mathrm{~cm}$. The EEM spectra were measured using a fluorescence spectrophotometer (F-7000, Hitachi High-Tech. Corp., Japan). The spectra were collected with subsequent scanning emission spectra from 250 to $550 \mathrm{~nm}$ at $5 \mathrm{~nm}$ increments by varying the excitation wavelength from 200 to $400 \mathrm{~nm}$ at $5 \mathrm{~nm}$ increments. The excitation and emission slits were maintained at $5 \mathrm{~nm}$ and the scanning speed was set at $1000 \mathrm{~nm} / \mathrm{min}$. The spectrum of pure water was used as the blank.

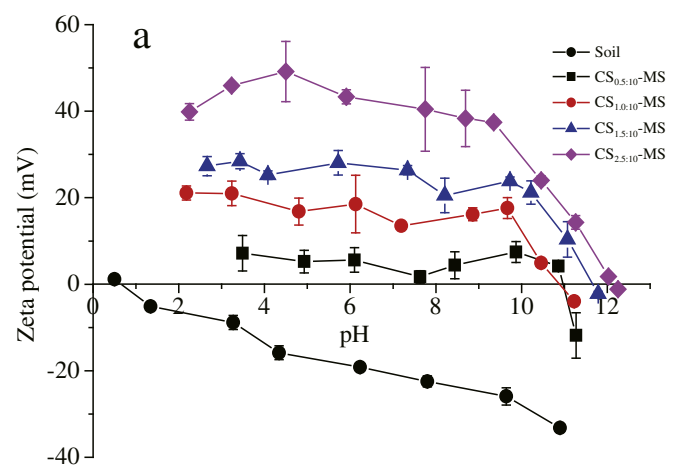

\section{Results}

\subsection{Surface charge of CS-MS particles}

After CS modification, the isoelectric point of soil particles was remarkably increased from pH 0.5 to above pH 10.8 (Fig. 1a), which made CS-MS particles positively charged under most natural water conditions. However, the surface charge of CS-MS particles varied with the charge density of CS. When high charge density CS was used, CS-MS particles possessed high surface charge (Fig. 1a) and gained a high ability of charge neutralization under natural water conditions. When $21 \mathrm{mg}$ CS-MS (20 mg soil modified with $1 \mathrm{mg} \mathrm{CS}$ ) was added to $200 \mathrm{~mL}$ M. aeruginosa solution with $6.4 \times 10^{8}$ cells, an increase was caused in the surface charge of algal cells (Fig. 1b). The cell surface charge was neutralized and increased from $37.5 \mathrm{mV}$ to $-33.0,-29.8,-20.2$ and $+1.2 \mathrm{mV}$ in $\mathrm{CS}_{0.5: 10}-\mathrm{MS}$, $\mathrm{CS}_{1.0: 10} \mathrm{MS}, \mathrm{CS}_{1.5: 10} \mathrm{MS}$ and $\mathrm{CS}_{2.5: 10} \mathrm{MS}$ treatments, respectively (Fig. 1b).

\subsection{Algal flocculation using CS-MSs}

After CS-MS was added, a maximum removal efficiency of about $85 \%$ for $M$. aeruginosa cells was achieved, but the optimal CS dosage varied greatly depending on its charge density, which was 60, 40 and $15 \mathrm{mg} / \mathrm{L}$ for $\mathrm{CS}_{0.5: 10}, \mathrm{CS}_{1.0: 10}$ and $\mathrm{CS}_{1.5: 10}$, respectively. In $\mathrm{CS}_{2.5: 10}$-MS treatment, the removal efficiency just maximally reached $76 \%$ at the CS dosage of $5 \mathrm{mg} / \mathrm{L}$. Once CS was overdosed, the removal efficiency exhibited a deceasing trend (Fig. 2a). As the CS dosage further increased to $80 \mathrm{mg} / \mathrm{L}$, the removal efficiency gradually decreased to $81 \%, 66 \%$ and $31 \%$ in $\mathrm{CS}_{0.5: 10}-\mathrm{MS}, \mathrm{CS}_{1.0: 10}-\mathrm{MS}$ and $\mathrm{CS}_{1.5: 10}$-MS treatments, respectively; in contrast, the removal efficiency in $\mathrm{CS}_{2.5: 10}$-MS treatment dropped sharply and reached less than $10 \%$ at the $80 \mathrm{mg} / \mathrm{L}$ of CS (Fig. 2a). The surface charge of algal cells as a function of CS dosage was measured. As the CS dosage increased, the cell surface charge was increased and charge reversal occurred around the optimal dosage of CS (Fig. 2b). At the $80 \mathrm{mg} / \mathrm{L}$ of CS, the cell surface charge reached $+4.4,+8.9,+15.6$ and $+26.4 \mathrm{mV}$ in $\mathrm{CS}_{0.5: 10}$-MS, $\mathrm{CS}_{1.0: 10}-\mathrm{MS}, \mathrm{CS}_{1.5: 10}-\mathrm{MS}$ and $\mathrm{CS}_{2.5: 10}-\mathrm{MS}$ treatments, respectively.

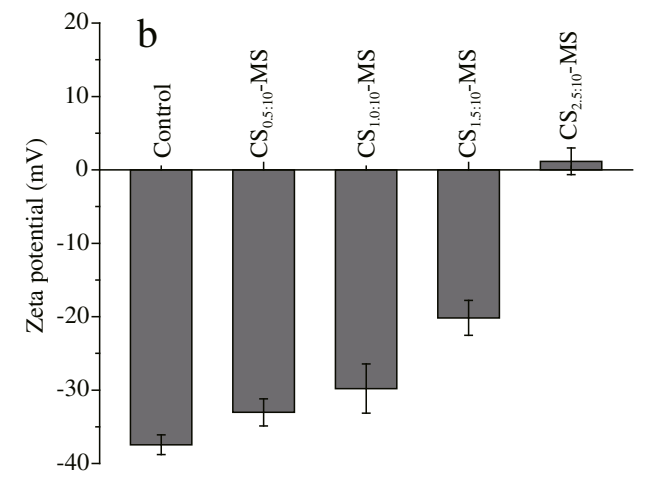

Fig. 1 - Surface charge of soil particles after cationic starch (CS) modification (a) and the increase of M. aeruginosa surface charge after the addition of cationic starch modified soils (CS-MSs) (b). Error bars indicate standard deviations. 

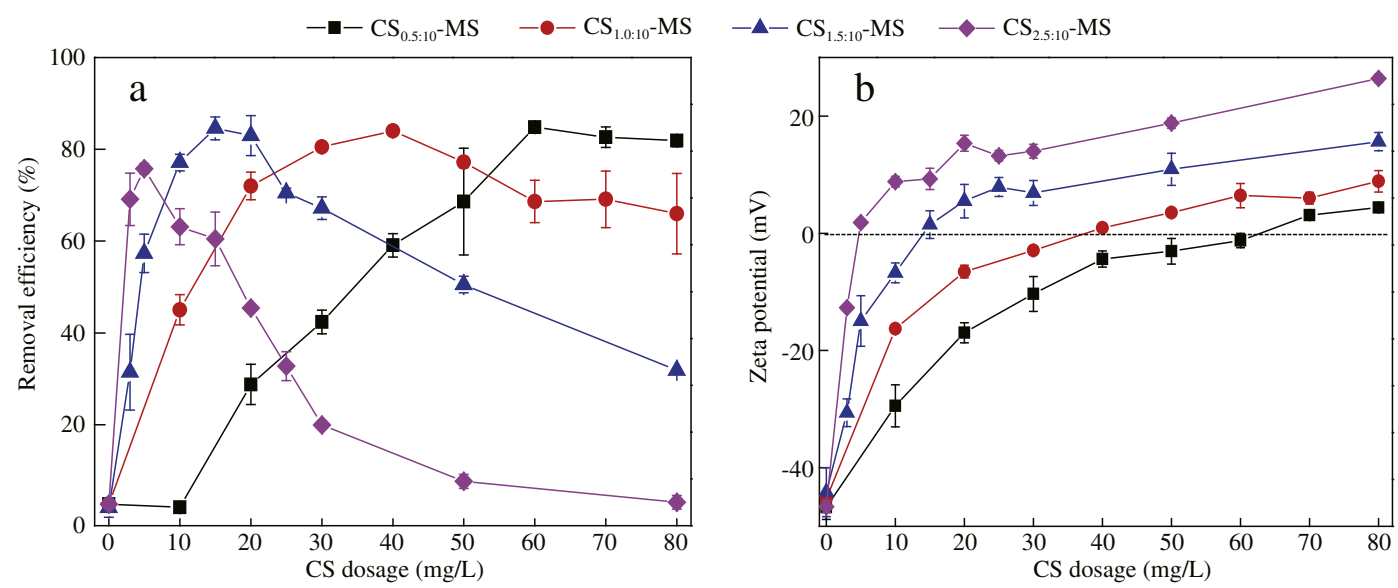

Fig. 2 - Algal removal efficiency (a) and surface charge of algal cells (b) at different dosages of CS. The soil concentration was fixed to $100 \mathrm{mg} / \mathrm{L}$. Error bars indicate standard deviations.

\subsection{DOC and $\mathrm{UV}_{254}$}

After algal removal, the DOC in algal solution showed a decrease and the use of higher charge density CS yielded a greater DOC reduction. The DOC was decreased from 3.4 to 3.0, 2.2 and $1.7 \mathrm{mg} / \mathrm{L}$ in $\mathrm{CS}_{1.0: 10}-\mathrm{MS}, \mathrm{CS}_{1.5: 10}-\mathrm{MS}$ and $\mathrm{CS}_{2.5: 10}-\mathrm{MS}$ treatments, respectively. However, the use of low charge density CS resulted in the DOC increase after algal removal. The DOC in $\mathrm{CS}_{0.5: 10}$-MS treatment was increased from 3.4 to $3.9 \mathrm{mg} / \mathrm{L}$ (Fig. 3). The $\mathrm{UV}_{254}$ reduction was observed in all the treatments, which was enhanced by higher charge density CS. After algal removal, the $\mathrm{UV}_{254}$ was decreased from 0.16 to 0.14 , $0.11,0.10$ and 0.08 in $\mathrm{CS}_{0.5: 10}-\mathrm{MS}, \mathrm{CS}_{1.0: 10}-\mathrm{MS}, \mathrm{CS}_{1.5: 10}-\mathrm{MS}$ and $\mathrm{CS}_{2.5: 10}$-MS treatments, respectively. The soil-only treatment could also lead to limited DOC (from 3.4 to $2.8 \mathrm{mg} / \mathrm{L}$ ) and $\mathrm{UV}_{254}$ (from 0.16 to 0.15 ) reductions in algal solution (Fig. 3).

\subsection{EEM fluorescence spectra}

One main peak at 270-285/320-345 nm (Ex/Em) was observed from the EEM fluorescence spectra of algal solution (Fig. 4), which were identified as soluble microbial by-product-like organics, including tyrosine-, tryptophan and protein-like components (Osburn et al., 2012; Guo et al., 2010). After algal removal, the peak intensity showed a decrease, suggesting that the soluble organics were removed by CS-MSs during flocculation-sedimentation process. The removal of these organics was enhanced by CS with the higher charge density (Fig. 4). When $\mathrm{CS}_{0.5: 10}, \mathrm{CS}_{1.0: 10}, \mathrm{CS}_{1.5: 10}$ and $\mathrm{CS}_{2.5: 10}$ were used in MSs, the peak intensity was decreased from 110.4 to $98.5,78.5$, 73.1 and 33.9, respectively. In soil-only treatment, the peak intensity was also decreased to 80.2.

\section{Discussion}

\subsection{Charge density and the optimal dosage of CS}

Charge neutralization is essential in creating algal flocculation potential by eliminating energy barrier for the aggregation between flocculants and algae particles (Liu et al., 2010; Phoochinda et al., 2004). When CS with the higher charge density was used, CS-MS particles possessed the higher surface charge (Fig. 1a) and gained a higher ability of charge

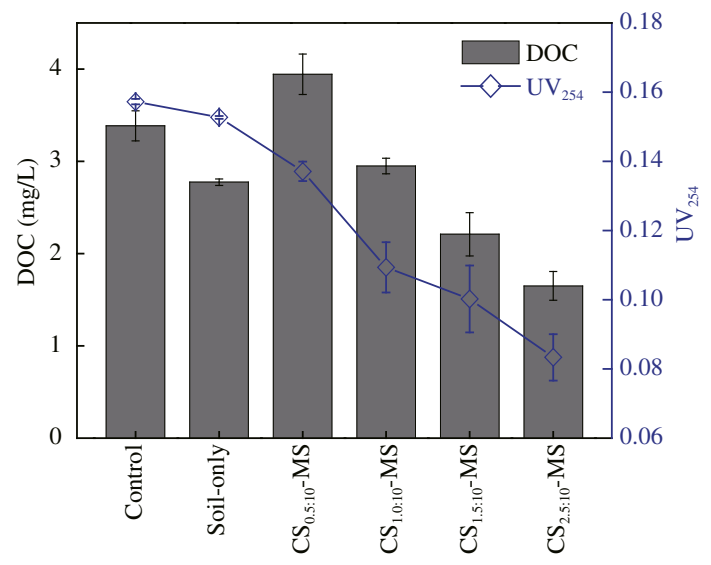

Fig. 3 - The changes of dissolved organic carbon (DOC) and $U_{254}$ in algal solution after algal removal at the optimal dosage of CS. The soil concentration was fixed to $100 \mathrm{mg} / \mathrm{L}$. Error bars indicate standard deviations. 

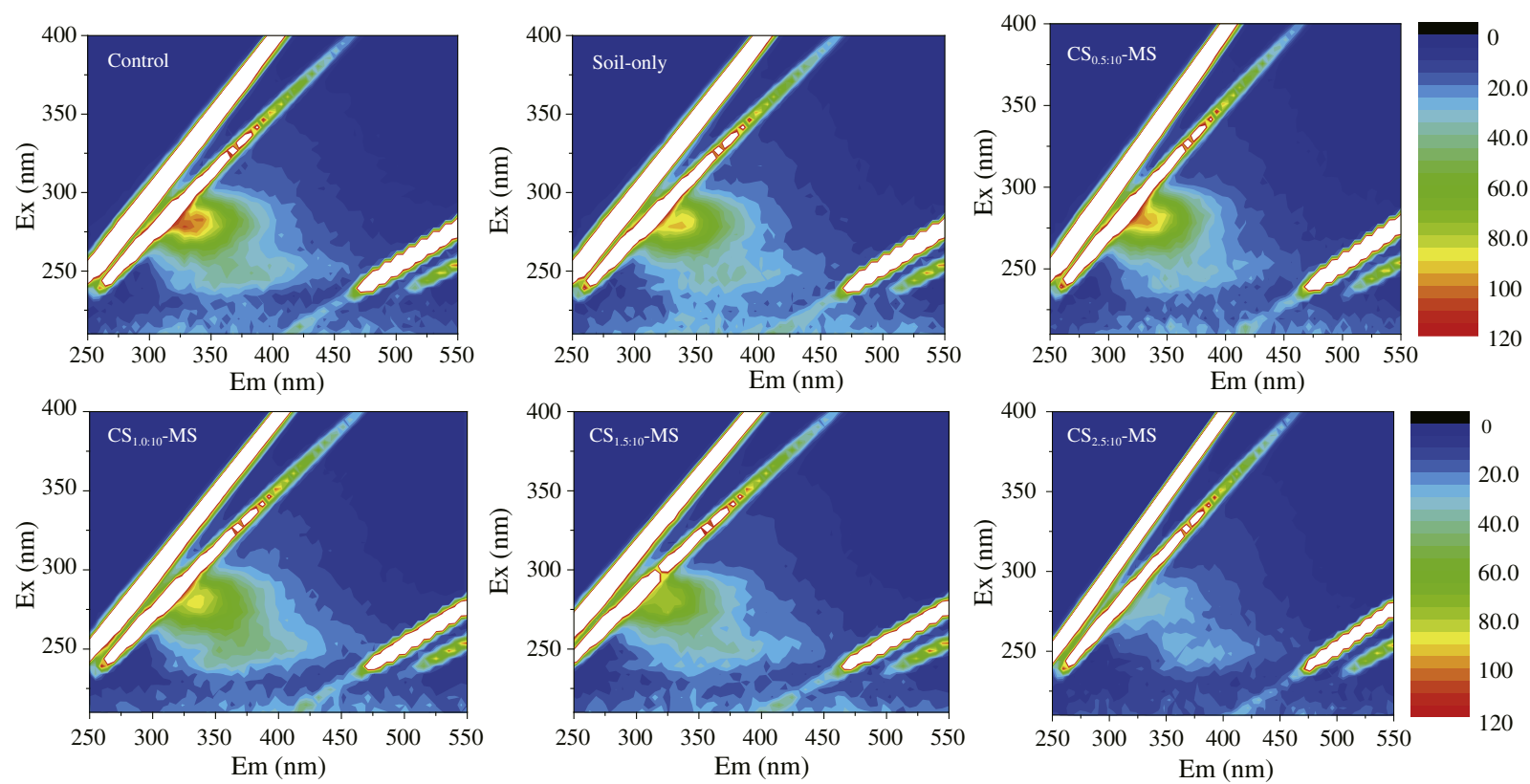

Fig. 4 - Excitation-emission matrix (EEM) fluorescence spectra of algal solution after algal removal using CS-MSs.

neutralization (Fig. 1b). The optimal algal flocculation occurred around the point of total charge neutralization (zeta potential close to zero, Fig. 2b). Thus, CS-MSs with the higher charge neutralization ability achieved effective algal removal at a lower CS loading, simply because, for a given dosage, they can deliver more positive charges to the cell surface. At the soil concentration of $100 \mathrm{mg} / \mathrm{L}$, the optimal CS dosage for the removal of $3.2 \times 10^{9} \mathrm{M}$. aeruginosa cells/L followed the order of $\mathrm{CS}_{0.5: 10}>\mathrm{CS}_{1.0: 10}>\mathrm{CS}_{1.5: 10}>\mathrm{CS}_{2.5: 10}$, which was $60,40,15$ and $5 \mathrm{mg} / \mathrm{L}$, respectively (Fig. 2a).

Based on the dosage and charge density of CS, algal removal efficiency and cell surface charge are re-plotted against positive charges in Fig. 5. It further indicated that positive charges play a key role in algal flocculation and the data sets take on a similar shape in each CS-MS treatment. As the positive charge dosage increased, algal removal efficiency increased and reached the maximum at the charge dosage of $0.9 \times 10^{12} \mathrm{meq} / \mathrm{cell}$. The cell surface charge was simultaneously increased from -46.2 to $0 \mathrm{mV}$. Once positive charges were overdosed, the removal efficiency decreased, since the reversal of cell surface charge (Fig. $2 b$ ) potentially reintroduced the electrostatic repulsion and prevented aggregation between CS-MS and algae particles (Jangkorn et al., 2011; Mosse et al., 2012; Shi et al., 2015). Hence, to achieve effective algal removal using MSs, the modifier loading mainly depended on the charge density. The loadings of low charge density organic modifiers are often high to provide enough positive charges, which potentially introduce substantial amount of organic matters into the receiving water. It is important to notice that flocculants with excessively high charge density are either not recommended to be used as soil modifiers. The low modifier loadings cannot offer adequate macromolecular chains for bridging effect in algal flocculation and may lead to limited algal removal (e.g., CS $_{2.5: 10}$ in Fig. 2a) (Li and Pan, 2013; Zou et al., 2005). Additionally, a small change in the loading of high charge density modifier can lead to significant differences in the amount of positive charges provided, which results in a

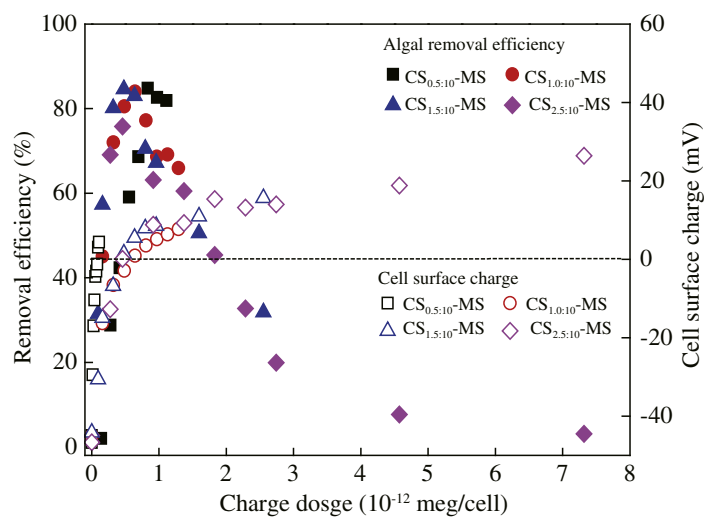

Fig. 5 - Algal removal efficiency and cell surface charge at different dosages of positive charge. 
narrow dosage range for effective algal removal (e.g., $\mathrm{CS}_{2.5: 10}$ in Fig. 2a). This hinders the application of MSs in fields where precise dosage control is often difficult.

\subsection{DOM after algal removal}

One main aim of algal removal is to prevent the occurrences of water quality deterioration and oxygen depletion in bloom waters. The application of organic algal flocculants poses a potential risk of DOM increase in water column, making algal removal become meaningless. However, DOC analysis indicated that the DOC content in algal solution was decreased after algal removal using CS-MSs. The DOC was decreased from 3.4 to 3.0, 2.3 and $1.7 \mathrm{mg} / \mathrm{L}$ in $\mathrm{CS}_{1.0: 10}-\mathrm{MS}, \mathrm{CS}_{1.5: 10}-\mathrm{MS}$ and $\mathrm{CS}_{2.5: 10}$-MS treatments, respectively (Fig. 3). The EEM fluorescence spectroscopy (Fig. 4) and $\mathrm{UV}_{254}$ analysis (Fig. 3) indicated that some soluble organic matters could be removed by CS-MSs during flocculation-sedimentation process, which contributed to the DOC reduction. Although $\mathrm{CS}_{10: 0.5}-\mathrm{MS}$ also exhibited the ability to remove some autochthonous DOM (Figs. 4 and 1), the high CS loading for the effective algal removal potentially introduced substantial amount of allochthonous organic matters into water column and increased DOC from 3.4 to $3.9 \mathrm{mg} / \mathrm{L}$ after algal removal (Fig. 3). Thus, in practice, organic flocculants with low charge density are not recommended to be used as soil modifiers in the MS method.

By optimizing the charge density of modifiers, algal cells can be flocculated and settled by MSs without increasing DOM in water column. This is necessary although not sufficient for the ecological restoration in eutrophic waters due to the decomposition of the settled organics at surface sediment. Other measures, such as capping treatments using oxygen loaded materials, should be jointly applied after flocculation. Previous studies indicated that nutrient fluxes across sediment-water interface can be reduced or even reversed and surface sediment conditions can be improved by proper capping treatments within a certain period of time (e.g., weeks) (Pan et al., 2012; Pan and Yang, 2012). This may create a window period for the restoration of submerged vegetation. Then, it is possible for the sealed organic matters in the capping layer to be turned into fertilizers for the growth of submerged vegetation (Pan et al., 2011b; Zhang et al., 2010).

\subsection{Co-removal potential of algal cells and DOM}

During algal blooms, high DOM accumulation is often observed due to the release and lysis of algal cells, which is an important nutrient pool in eutrophic waters (Nguyen et al., 2005; Ye et al., 2011). The co-removal of algal cells (particulate nutrients) and DOM (dissolved nutrients) may maximize the nutrient reduction and benefit the ecological restoration in eutrophic waters.

During algal flocculation using CS-MSs, the decrease in both $U_{254}$ value (Fig. 3) and EEM fluorescence peak intensity (Fig. 4) was observed, indicating that CS-MS flocculation has the potential to achieve the co-removal of algal cells and DOM. When CS with the higher charge density was used, more DOM could be removed at the lower optimal CS dosage for algal removal. The $\mathrm{UV}_{254}$ was decreased from 0.16 to 0.14 , $0.11,0.10$ and 0.08 (Fig. 3); and the fluorescence peak intensity at the Ex/Em of 275-280/320-345 $\mathrm{nm}$ was decreased from 110.4 to $98.5,78.5,73.1$ and 33.9 (Fig. 4) in $\mathrm{CS}_{0.5: 10}-\mathrm{MS}, \mathrm{CS}_{1.0: 10}-\mathrm{MS}$, $\mathrm{CS}_{1.5: 10} \mathrm{MS}$ and $\mathrm{CS}_{2.5: 10}$-MS treatments, respectively. This suggested that the use of higher charge density CS makes MS not only possess the higher ability of algal removal but also gain a higher ability of DOM removal. Previous studies reported that DOM flocculation is mainly operated by charge neutralization mechanism, which is similar to algal flocculation (Hussain et al., 2013; Lee and Westerhoff, 2006). There may exist competitive binding of algal cells and DOM to MSs, and the optimal flocculation of algal cells and DOM may occur at different dosages of CS. Further studies are required to explore the co-removal effect of algal cells and DOM using CS-MS flocculation in bloom waters. Soil particles play an important role in the DOC reduction during CS-MS flocculation. In the soil-only treatment, the DOC and $\mathrm{UV}_{254}$ decreased from 3.4 to $2.8 \mathrm{mg} / \mathrm{L}$ and from 0.16 to 0.15 , respectively (Fig. 3); and the fluorescence peak intensity at the Ex/Em of 275-280/ 320-345 nm decreased from 110.4 to 80.2 (Fig. 4b). However, contaminated soil (by heavy metals and fertilizers) is not recommended to be used. In fields, washing and particle fractionation method can be applied to select large amount of fine soil particles (Li and Pan, 2013).

\subsection{Implications for the development of soil modifiers}

In the MS method, modifiers make soil particles obtain charge neutralization ability to create algal flocculation potential. Our results demonstrated that the charge density of modifier affects its loading for effective algal removal and thereby DOM content in the treated bloom water. It is necessary to screen flocculants with right charge density to be used as soil modifiers. The charge density can be optimized by regulating the cationic monomer dosage in the production. Confirmation of the optimum one can be determined by jar tests before field applications. Some high charge density materials can be jointly used to facilitate charge neutralization to reduce the loadings of organic modifiers according to the bicomponent modification method ( $\mathrm{Li}$ and Pan, 2013, 2015). In the field, cyanobacterial cells often occur in colonies with several hundred micrometers in diameter, and water conditions (e.g., salinity, dissolved organic matter) are often different from synthetic media used in this study. Further study using natural bloom water is needed before the application of CS-MSs in fields, which is also important for the integration of the knowledge.

There are various polymers available for the production of cationic flocculants as soil modifiers, such as chitosan, tannin, polysaccharides and polyacrylamides (Yang et al., 2012; Wang et al., 2013a, 2013b). To produce eco-friendly geo-engineering materials, biodegradable natural polymers (e.g., polysaccharides) are preferred, while synthetic polymers (e.g., polyacrylamide) are not recommended to be used, since most synthetic polymer structures are resistant to biodegradation (Bolto and Gregory, 2007). Economic cost is often a main factor limiting large scale application of the method in fields. Cheaply available polymers (e.g., corn starch) should be used to reduce the material costs. Water $\mathrm{pH}$ often fluctuates during algal blooms and sometimes even increases as high as 9.5 (Wu et al., 2014). Cationic monomers with quaternary 
ammonium groups are preferred, since they cannot be easily dissociated after being grafted onto the polymer backbone as the $\mathrm{pH}$ condition changes (Bolto and Gregory, 2007).

\section{Conclusions}

CS could turn soil particles into effective flocculants for the sedimentation removal of cyanobacterial cells. The charge density of CS has great influence on DOM content in the treated water. Some soluble organic matters could be removed during CS-MS flocculation and lead to DOM reduction. However, the use of low charge density CS posed the potential risk of DOM increase in the receiving water due to the high CS loading for effective algal removal. By optimizing the charge density of CS, it is possible to achieve DOM content control in the CS-MS treated bloom water. Further study using natural bloom water is needed before the application of CS-MSs in the field.

\section{Acknowledgments}

This study is supported by the Strategic Priority Research Program of the Chinese Academy of Sciences (No. XDA09030203) and the Science Promotion Program of Research Center for Eco-Environmental Sciences, Chinese Academy of Sciences (No. YSW2013B05).

\section{R E F E R E N E S}

Ahmad, F.B., Williams, P.A., Doublier, J.L., Durand, S., Buleon, A., 1999. Physico-chemical characterisation of sage starch. Carbohydr. Polym. 38 (4), 361-370.

Bolto, B., Gregory, J., 2007. Organic polyelectrolytes in water treatment. Water Res. 41 (11), 2301-2324.

Bushaw, K.L., Zepp, R.G., Tarr, M.A., SchulzJander, D., Bourbonniere, R.A., Hodson, R.E., et al., 1996. Photochemical release of biologically available nitrogen from aquatic dissolved organic matter. Nature 381 (6581), 404-407.

Chen, H., Pan, G., Zhang, M.M., 2004. Effect of growth phase on the flocculation of algal cells using clays. Environ. Sci. 25 (6), 148-151.

Chen, W., Song, L.R., Gan, N.Q., Li, L., 2006. Sorption, degradation and mobility of microcystins in Chinese agriculture soils: risk assessment for groundwater protection. Environ. Pollut. 144 (3), 752-758

Dai, G.F., Zhong, J.Y., Song, L.R., Guo, C.J., Gan, N.Q., Wu, Z.B., 2015. Harmful algal bloom removal and eutrophic water remediation by commercial nontoxic polyamine-co-polymeric ferric sulfate-modified soils. Environ. Sci. Pollut. Res. 22 (14), 10636-10646.

Evans, C.D., Monteith, D.T., Cooper, D.M., 2005. Long-term increases in surface water dissolved organic carbon: observations, possible causes and environmental impacts. Environ. Pollut. 137 (1), 55-71.

Guo, W.D., Xu, J., Wang, J.P., Wen, Y.R., Zhuo, J.F., Yan, Y.C., 2010. Characterization of dissolved organic matter in urban sewage using excitation emission matrix fluorescence spectroscopy and parallel factor analysis. J. Environ. Sci. 22 (11), 1728-1734.

Hussain, S., van Leeuwen, J., Chow, C., Beecham, S., Kamruzzaman, M., Wang, D.S., et al., 2013. Removal of organic contaminants from river and reservoir waters by three different aluminum-based metal salts: coagulation adsorption and kinetics studies. Chem. Eng. J. 225, 394-405.

Jangkorn, S., Kuhakaew, S., Theantanoo, S., Klinla-Or, H., Sriwiriyarat, T., 2011. Evaluation of reusing alum sludge for the coagulation of industrial wastewater containing mixed anionic surfactants. J. Environ. Sci. 23 (4), 587-594.

Kam, S.K., Gregory, J., 1999. Charge determination of synthetic cationic polyelectrolytes by colloid titration. Colloids Surf. A 159 (1), 165-179.

Lee, W., Westerhoff, P., 2006. Dissolved organic nitrogen removal during water treatment by aluminum sulfate and cationic polymer coagulation. Water Res. 40 (20), 3767-3774.

Li, L., Pan, G., 2013. A universal method for flocculating harmful algal blooms in marine and fresh waters using modified sand. Environ. Sci. Technol. 47 (9), 4555-4562.

Li, L., Pan, G., 2015. Cyanobacterial bloom mitigation using proteins with high isoelectric point and chitosan-modified soil (in press). J. Appl. Phycol. http://dx.doi.org/10.1007/s10811015-0598-1.

Li, L., Zhang, H.G., Pan, G., 2015. Influence of zeta potential on the flocculation of cyanobacteria cells using chitosan modified soil. J. Environ. Sci. 28, 47-53.

Lin, Q.T., Qian, S., Li, C.J., Pan, H.P., Wu, Z.Y., Liu, G.G., 2012. Synthesis, flocculation and adsorption performance of amphoteric starch. Carbohydr. Polym. 90 (1), 275-283.

Liu, Q.Q., Le, X.C., 2015. Genotoxic effects of microcystins mediated by nitric oxide and mitochondria. J. Environ. Sci. 31, 206-208.

Liu, G.F., Fan, C.X., Zhong, J.C., Zhang, L., Ding, S.M., Yan, S.H., et al., 2010. Using hexadecyl trimethyl ammonium bromide (CTAB) modified clays to clean the Microcystis aeruginosa blooms in Lake Taihu, China. Harmful Algae 9 (4), 413-418.

Lu, X., Fan, C.X., He, W., Deng, J.C., Yin, H.B., 2013.

Sulfur-containing amino acid methionine as the precursor of volatile organic sulfur compounds in algae-induced black bloom. J. Environ. Sci. 25 (1), 33-43.

Lürling, M., van Oosterhout, F., 2013. Controlling eutrophication by combined bloom precipitation and sediment phosphorus inactivation. Water Res. 47 (17), 6527-6537.

Mackay, E.B., Maberly, S.C., Pan, G., Reitzel, K., Bruere, A., Corker, N., et al., 2014. Geoengineering in lakes: welcome attraction or fatal distraction? Inland Waters 4 (4), 349-356.

Mermillod-Blondin, F., Nogaro, G., Datry, T., Malard, F., Gibert, J., 2005. Do tubificid worms influence the fate of organic matter and pollutants in stormwater sediments? Environ. Pollut. 134 (1), 57-69.

Mosse, W.K.J., Boger, D.V., Simon, G.P., Garnier, G., 2012. Effect of cationic polyacrylamides on the interactions between cellulose fibers. Langmuir 28 (7), 3641-3649.

Mukherjee, S., Mukhopadhyay, S., Pariatamby, A., Hashim, M.A., Sahu, J.N., Sen Gupta, B., 2014. A comparative study of biopolymers and alum in the separation and recovery of pulp fibres from paper mill effluent by flocculation. J. Environ. Sci. 26 (9), 1851-1860.

Ndabigengesere, A., Narasiah, K.S., 1998. Quality of water treated by coagulation using Moringa oleifera seeds. Water Res. 32 (3), 781-791.

Nguyen, M.L., Westerhoff, P., Baker, L., Hu, Q., Esparza-Soto, M., Sommerfeld, M., 2005. Characteristics and reactivity of algae-produced dissolved organic carbon. J. Environ. Eng. ASCE 131 (11), 1574-1582.

Osburn, C.L., Handsel, L.T., Mikan, M.P., Paerl, H.W., Montgomery, M.T., 2012. Fluorescence tracking of dissolved and particulate organic matter quality in a river-dominated estuary. Environ. Sci. Technol. 46 (16), 8628-8636.

Pan, G., Yang, B., 2012. Effect of surface hydrophobicity on the formation and stability of oxygen nanobubbles. ChemPhysChem 13 (8), 2205-2212. 
Pan, G., Zou, H., Chen, H., Yuan, X.Z., 2006. Removal of harmful cyanobacterial blooms in Taihu Lake using local soils. III. Factors affecting the removal efficiency and an in situ field experiment using chitosan-modified local soils. Environ. Pollut. 141 (2), 206-212.

Pan, G., Chen, J., Anderson, D.M., 2011a. Modified local sands for the mitigation of harmful algal blooms. Harmful Algae 10 (4), 381-387.

Pan, G., Yang, B., Wang, D., Chen, H., Tian, B.H., Zhang, M.L., et al., 2011b. In-lake algal bloom removal and submerged vegetation restoration using modified local soils. Ecol. Eng. 37 (2), 302-308.

Pan, G., Dai, L.C., Li, L., He, L.C., Li, H., Bi, L., et al., 2012. Reducing the recruitment of sedimented algae and nutrient release into the overlying water using modified soil/sand flocculation-capping in eutrophic lakes. Environ. Sci. Technol. 46 (9), 5077-5084.

Phoochinda, W., White, D.A., Briscoe, B.J., 2004. An algal removal using a combination of flocculation and flotation processes. Environ. Technol. 25 (12), 1385-1395.

Qu, X.X., Xie, L., Lin, Y., Bai, Y.C., Zhu, Y.R., Xie, F.Z., et al., 2013. Quantitative and qualitative characteristics of dissolved organic matter from eight dominant aquatic macrophytes in Lake Dianchi, China. Environ. Sci. Pollut. Res. 20 (10), 7413-7423.

Renault, F., Sancey, B., Badot, P.M., Crini, G., 2009. Chitosan for coagulation/flocculation processes - an eco-friendly approach. Eur. Polym. J. 45 (5), 1337-1348.

Shi, W.Q., Tan, W.Q., Wang, L.J., Pan, G., 2015. Removal of Microcystis aeruginosa using cationic starch modified soils (in press). Water Res. http://dx.doi.org/10.1016/j.watres.2015.06. 029.

Spears, B.M., Lurling, M., Yasseri, S., Castro-Castellon, A.T., Gibbs, M., Meis, S., et al., 2013. Lake responses following lanthanum-modified bentonite clay (Phoslock $®$ ) application: an analysis of water column lanthanum data from 16 case study lakes. Water Res. 47 (15), 5930-5942.

Spears, B.M., Maberly, S.C., Pan, G., Mackay, E., Bruere, A., Corker, N., et al., 2014. Geo-engineering in lakes: a crisis of confidence? Environ. Sci. Technol. 48 (17), 9977-9979.
Tian, F., Zhou, J.Y., Sun, Z.W., Cai, Z.P., Xu, N., An, M., et al., 2014. Inhibitory effects of Chinese traditional herbs and herb-modified clays on the growth of harmful algae, Phaeocystis globosa and Prorocentrum donghaiense. Harmful Algae 37, 153-159.

Wang, J.P., Yuan, S.J., Wang, Y., Yu, H.Q., 2013a. Synthesis, characterization and application of a novel starch-based flocculant with high flocculation and dewatering properties. Water Res. 47 (8), 2643-2648.

Wang, L., Liang, W.Y., Yu, J., Liang, Z.X., Ruan, L.L., Zhang, Y.C., 2013b. Flocculation of Microcystis aeruginosa using modified Larch Tannin. Environ. Sci. Technol. 47 (11), 5771-5777.

Wang, L.P., Liu, L.S., Zheng, B.H., 2013c. Eutrophication development and its key regulating factors in a water-supply reservoir in North China. J. Environ. Sci. 25 (5), 962-970.

Wu, Y.L., Li, L., Gan, N.Q., Zheng, L.L., Ma, H.Y., Shan, K., et al., 2014. Seasonal dynamics of water bloom-forming Microcystis morphospecies and the associated extracellular microcystin concentrations in large, shallow, eutrophic Dianchi Lake. J. Environ. Sci. 26 (9), 1921-1929.

Yang, Z., Shang, Y.B., Huang, X., Chen, Y.C., Lu, Y.B., Chen, A.M., et al., 2012. Cationic content effects of biodegradable amphoteric chitosan-based flocculants on the flocculation properties. J. Environ. Sci. 24 (8), 1378-1385.

Ye, L.L., Shi, X., Wu, X.D., Zhang, M., Yu, Y., Li, D.M., et al., 2011. Dynamics of dissolved organic carbon after a cyanobacterial bloom in hypereutrophic Lake Taihu (China). Limnologica 41 (4), 382-388.

Zhang, L.Y., Li, K.Y., Liu, Z.W., Middelburg, J.J., 2010. Sedimented cyanobacterial detritus as a source of nutrient for submerged macrophytes (Vallisneria spiralis and Elodea nuttallii): an isotope labeling experiment using ${ }^{15} \mathrm{~N}$. Limnol. Oceanogr. 55 (5), 1912-1917.

Zou, H., Pan, G., Chen, H., 2005. Effects of ionic strength on the flocculation and removal of cyanobacterial cells of Microcystis aeruginosa by clays. Environ. Sci. 26 (2), 148-151. 